Nikolai S. Chebykin ${ }^{a,}{ }^{*}$, Ivan P. Sandalov ${ }^{b}$, Dmitry A. Zamyatin a , Sergey L. Votyakov ${ }^{a}$

a Zavaritsky Institute of Geology and Geochemistry UB RAS, 15 Vonsovskogo st., 620016, Ekaterinburg, Russia

${ }^{b}$ Plaurum AO "Ekaterinburg non-ferrous metals processing plant", 131 Uspensky Ave., Verhnyaya Pyshma, 624088, Sverdlovsk region, Russia *email: tchebykinnikolai@yandex.ru

\title{
Determination of platinum group elements in catalysts recycling products by SEM with energy dispersive spectrometer
}

Analysis of platinum group elements (PGE) extracted from various catalysts used in the car, petroleum and chemical industries requires use of microanalytical methods. PGE content in the platinum powder concentrates K176 and K177 was studied by SEM-EDS. The content of main elements was determined using analytical lines Fe Kal, Si Kal, Sn La1, Pt Lal, Re Lal. The obtained data for the chemical composition are in good agreement with the result obtained by $X$-ray fluorescence analysis and ICP-MS method. Powdered platinum concentrates are considered to be ferrosilicide ( $\mathrm{FeSi}$ ), where PGE are localized at the phase boundaries and in separate patches of the K176 sample, or distributed over the volume of particles in the K177 sample.

Keywords: PGE; platinum powder concentrate; SEM-EDS; microanalysis; $X$-ray lines

Received: 24.12.2019. Accepted: 06.03.2020. Published: 31.03.2020.

(C) Chebykin N. S., Sandalov I. P., Zamyatin D. A., Votyakov S. L., 2020

\section{Introduction}

High cost of platinum group elements (PGE) dictates the economic feasibility of their recovery from various catalysts which had been used in car, petroleum and chemical industries. In order to extract PGE, Plaurum AO "Ekaterinburg non-ferrous metals processing plant" (JSC EZOCM) applied a smelting technology on an iron collector using a Tetronics plasma furnace with the subsequent processing of the collector in acids [1]. The quantitative electron probe microanalysis of the processed powdered platinum concentrate, in order to determine its compo- sition is difficult due to the rough surface of the particles and the significant overlaps of the X-ray emission lines of PGE. Therefore development of a microanalysis method for the determination of PGE content in the products of catalyst recycling allow to optimize the technology and assess the efficiency of metal extraction.

The aim of the work is to develop a microanalysis technique for the determination of PGE content in platinum powder concentrate and in the products of its recycling using scanning electron microscopy (SEM) equipped with an energy disper- 
sive spectrometer (EDS), as well as to test the modified technique for the examina-

\section{Samples and Methods}

The powder concentrate samples, denoted as K176-177 (see Fig. 1) were obtained by melting of catalysts with lime, quartz sand, magnetite and coke. The samples differ in melting parameters and charge composition. The samples were placed on a conductive adhesive tape and studied using a scanning electron microscope JEOL JSM-6390LV equipped with

\section{Results and Discussion}

Semi-quantitative analysis of the PGE content was performed using a standard sample of metallic cobalt with consequent normalization of total elements content to $100 \%$. We used both reference materials (minerals hematite and diopside for analysis of Fe and Si content, respectively) and pure metal standards (such as, Sn, Pt, and Re) for $\mathrm{X}$-ray peak intensity calibration. The content of the main elements (Fe, Si, Sn, Pt, Re) was determined using the following analytical lines of the X-ray spectrum: Fe Kal, Si Ka1, Sn La1, Pt La1, Re Lal (see Fig. 2b). The lines for the two last of the listed PGEs do not overlapped with $\mathrm{X}$-ray lines for $\mathrm{Al}$, tion of chemical composition and morphological characteristics of the samples.

EDS Oxford INCA X-Max80. The used working distance was equal to $10 \mathrm{~mm}$, accelerating voltage of $30 \mathrm{kV}$ and accumulation time of $60 \mathrm{~s}$. The refinement of obtained X-ray spectra was performed using the Aztec v.3.1 software (including modeling of background by integral line and $\mathrm{X}$-ray peaks by Voigt profile) [2].

$\mathrm{Cr}, \mathrm{Ti}, \mathrm{V}, \mathrm{Ca}, \mathrm{Cl}$, the presence of which is typical for studied samples (Fig. 3); their content was measured by the corresponding $\mathrm{X}$-ray lines $\mathrm{Al} \mathrm{Ka1,} \mathrm{Cr} \mathrm{Ka1,} \mathrm{Ti} \mathrm{Kal,} \mathrm{V} \mathrm{Kal,}$ $\mathrm{Ca} \mathrm{Ka1,} \mathrm{Cl} \mathrm{Kal.}$

In order to determine qualitatively (or semi-quantitatively) the average chemical composition of the samples, we have studied a region with the area of $1.5 \mathrm{~mm}^{2}$ which contained about 300-400 particles of powder in scanning mode. The surface of the particles in the samples exhibited either complex branched structure (K176) or rounded shape with developed edges (K177). The size of particles in the sam-

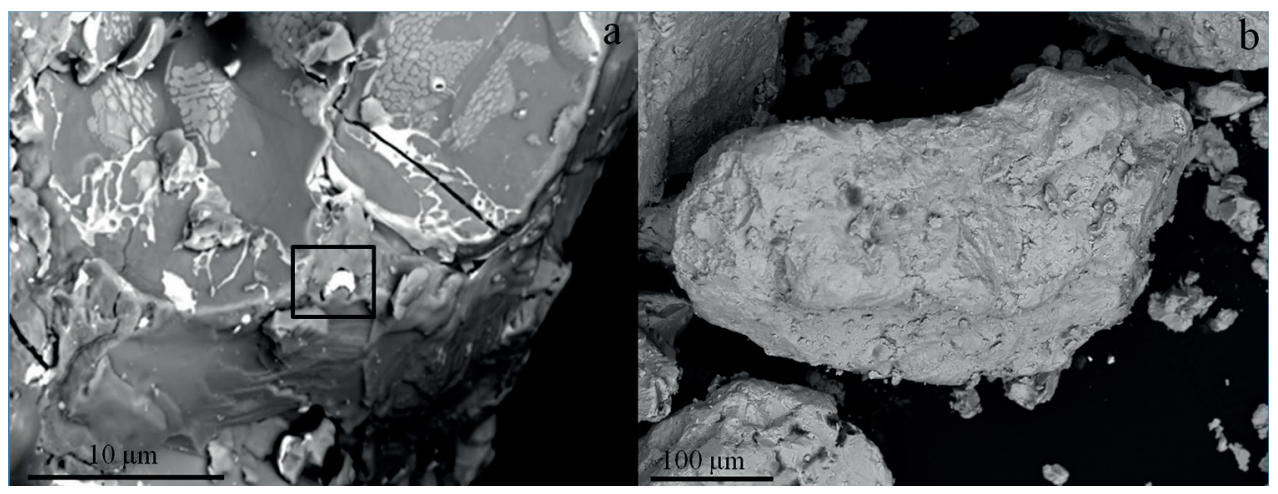

Fig. 1. BSE images of platinum concentrate particles (a, b - samples K176 and K177). The rectangle area separated in image (a) - corresponded to the plot for the sample K176, shown in Fig. 3a 
ples varied from 50 to 300 microns. The content of main elements in the K176 sample can be represented as: $\mathrm{Fe}=81.7$, $\mathrm{Si}=12.1, \mathrm{Pt}=2.4, \mathrm{Sn}=1.3$ wt.\%; whereas the detected impurities are: $\mathrm{Al}, \mathrm{Cr}, \mathrm{Ti}, \mathrm{V}$, $\mathrm{Cl}$. The sample $\mathrm{K} 177$ contains $\mathrm{Fe}=77.7$, $\mathrm{Si}=16.2, \mathrm{Pt}=1.5, \mathrm{Re}=2.3$ wt.\% as main elements and the detected impurities are: $\mathrm{Al}, \mathrm{Ti}, \mathrm{V}, \mathrm{Ca}, \mathrm{Cl}$. The relative standard deviation $(\Delta)$ for the elements' content in the samples determined in the scan- ning mode is 1.3 (1.1 wt.\%), 5.0 (0.8 wt.\%), 4.3 (0.1 wt.\%), and 4.9 (0.1 wt.\%) \%, for $\mathrm{Fe}, \mathrm{Si}, \mathrm{Pt}$, and Re respectively. The chemical composition of Fe, Si, Pt, Re obtained by SEM-EDS within these standard deviations completely coincides with the values obtained in the EZOCM laboratory using X-ray fluorescence analysis (XRF) $(\mathrm{Fe}=77.1 \mathrm{wt} . \%, \mathrm{Si}=15.9 \mathrm{wt} . \%)$ and inductively coupled plasma mass spectrometry $(\mathrm{ICP}-\mathrm{MS})(\mathrm{Pt}=1.6$ wt.\%, $\mathrm{Re}=2.5$ wt.\% $)$

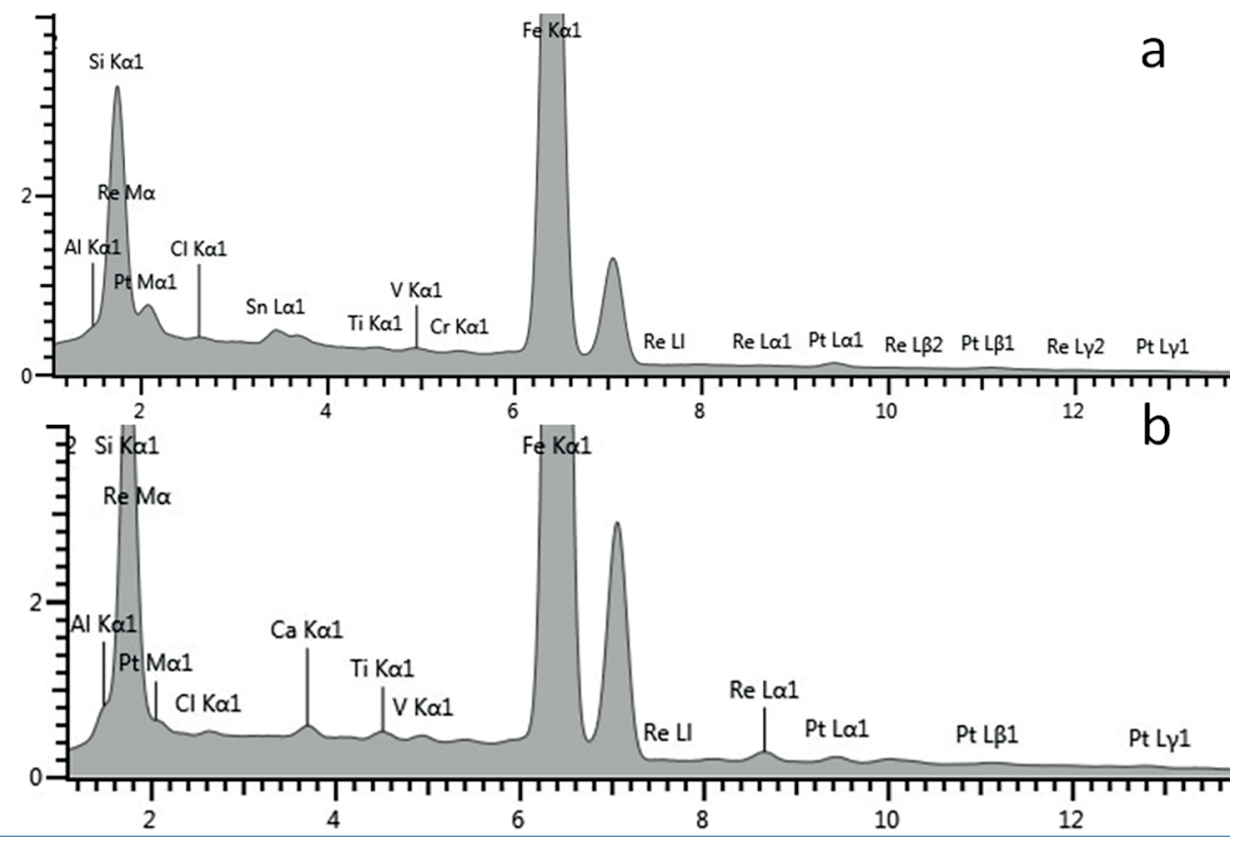

Fig. 2. X-ray spectra for the K176 (a) and K177 (b) samples. Scanning mode, the scanning region area of $1.5 \mathrm{~mm}^{2}$
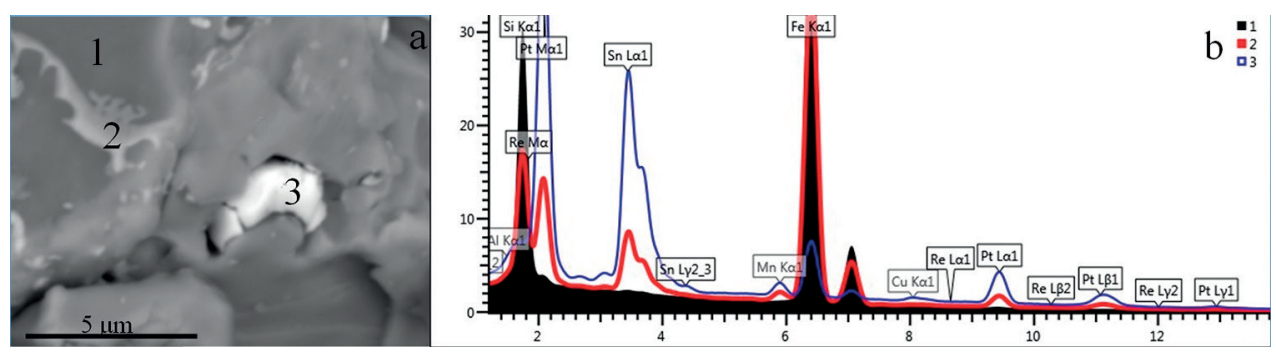

Fig. 3. The BSE image for the K176 (a) sample, X-ray spectra reflects the presence of three phases (b). 1 - dark-grey phase on BSE image (the main phase in the volume); 2 - middlegrey (intermediate); 3 - bright-grey (blotches) 
Table 1

The chemical composition of the phases detected in the K176 sample by SEM-EDS

\begin{tabular}{c|l|c|c|c|c}
\hline \multirow{2}{*}{ Phase } & \multirow{2}{*}{ Brightness on BSE } & \multicolumn{4}{|c}{ Concentration $^{*}$, wt. \% } \\
\cline { 3 - 6 } & & $\mathrm{Fe}$ & $\mathrm{Si}$ & $\mathrm{Sn}$ & $\mathrm{Pt}$ \\
\hline 1 & Dark-grey & $80.2-85.7$ & $12.5-17.6$ & $<1$ & $0.7-1.3$ \\
\hline 2 & Middle-grey & $60.0-85.7$ & $3.0-9.2$ & $1.1-13.7$ & $6.9-16.0$ \\
\hline 3 & Bright-grey & $8.5-16.0$ & $<1$ & $39.9-49.5$ & $38.6-39.3$ \\
\hline
\end{tabular}

* the variation in the data obtained as a result of three measurements in each phase.

for sample $\mathrm{K} 177$ and is close for sample $\mathrm{K} 176(\mathrm{Fe}=77.3 \mathrm{wt} . \%, \mathrm{Si}=15.6$ wt.\%, $\mathrm{Pt}=1.9$ wt.\%). The main reason for the discrepancy of the K176 sample is heterogeneity.

In order to identify the nature and chemical composition of phases that contained in different particles of the inhomogeneous K176 sample we used the mode of individual point analysis. The spatial resolution in this mode is $1-3$ microns. Three different phases inside the K176 sample (see Figs. 1, 3) with different BSE brightness were clearly distinguished: dark-grey (main phase inside the volume), middlegrey (intermediate) and bright-grey (separate blotches). It was found that the chemical composition of these phases varied significantly (see Table 1). The main elements are: $\mathrm{Fe}$ and $\mathrm{Si}$ in a dark-grey phase, $\mathrm{Fe}$ and $\mathrm{Pt}$ in a middle-grey phase, Pt and $\mathrm{Sn}$ in a bright-grey phase.

\section{Conclusions}

The results of the elaborated microanalysis technique by means of a scanning electron microscopy (SEM) equipped with an energy dispersive spectrometer (EDS) applied to measure the PGE content in powder catalysts recycling products were in good agreement with the result obtained by other methods and allow to demonstrate the redistribution of PGE after processing in plas-

ma furnace and acids. Based on the obtained data one can conclude that powdered platinum concentrates in the K176 and K177 samples are mainly ferrosilicide (FeSi) [3], and the platinum group elements are localized at the phase boundaries and in separate patches of the K176 sample, or distributed over the volume of particles in the K177 sample.

\section{Acknowledgements}

This work was supported by the theme of state agreement of IGG UB RAS (theme No. AAAA-A19-119071090011-6).

\section{References}

1. Borbat VF, Maslenitskij IN, Nikitin MV, Strizhko LS, Chugaev LV. Metallurgiya blagorodnyh metallov. Moscow: Metallurgiya; 1987. 432 p. Russian.

2. Briggs D, Seah MP. Practical surface analysis: By auger and x-ray photoelectron spectroscopy. New York: John Wiley \& Sons; 1983. 533 p.

3. Bannykh OA, Budberg PB, Alisova SP et al. Diagrammy sostoyaniya dvojnykh i mnogokomponentnykh sistem na osnove zheleza. Moscow: Metallurgiya; 1986. 440 p. Russian. 